\title{
«POR EL TRIUNFO DE LA CAUSA DE DIOS». LA REACCIÓN DE LA IGLESIA ANTE EL FRENTE POPULAR DE 1936*
}

\author{
POR \\ MANUEl Álvarez TARdío ${ }^{1}$ \\ Universidad Rey Juan Carlos
}

\section{RESUMEN}

Este artículo aborda el papel de la Iglesia católica durante los primeros meses de 1936. Su objetivo principal es contribuir a una mejor comprensión de la reacción de los obispos, los párrocos y las juntas de Acción Católica ante la formación de la unidad electoral de Frente Popular, teniendo presente la indisimulada división de algunas candidaturas antirrevolucionarias durante la campaña. Se han utilizado fuentes primarias y referencias de estudios locales y nacionales para alcanzar una perspectiva general de esa cuestión.

PALABRAS CLAVE: Iglesia; catolicismo; elecciones; Política; Historia; España; siglo XX; República.

\section{«POR EL TRIUNFO DE LA CAUSA DE DIOS». THE CATHOLIC CHURCH REACTED AGAINST THE POPULAR FRONT IN 1936 SPANISH ELECTIONS}

\begin{abstract}
This paper talks about the role of Spanish Catholic Church during the first months of 1936. The main point is to improve our understanding about the reaction of bishops, parish priests and Catholic Action boards after the formation of the Popular Front electoral unit. The undisguised division of some anti-revolutionary candidacies during the campaign is an important ingredient to analyze that reaction. Primary sources and references of local and national studies have been used to obtain a general perspective of the main issue.
\end{abstract}

KEY WORDS: Church; Catholicism; Politics; Elections; History; Spain; 20th Century; Republic.

Cómo CITAR ESTE ARTículo / CITATION: Álvarez Tardío, M. 2018. «'Por el triunfo de la causa de Dios'. La reacción de la Iglesia ante el Frente Popular de 1936». Hispania Sacra 70, 142: 649-659. https://doi.org/10.3989/hs.2018.044

$\begin{array}{ll}\text { Recibido/Received } & \text { 05-07-2016 } \\ \text { Aceptado/Accepted } & 11-07-2016\end{array}$

I

Barcelona, día 25 de enero de 1936. Quedaban algo más de veinte días para que todos los españoles, hombres y mujeres, pudieran ejercer su derecho al voto. Se iban a celebrar las terceras elecciones generales en apenas cinco años de Segunda República. La campaña estaba poniendo de manifiesto una gran capacidad de movilización por parte de los diferentes grupos que se disputaban el apoyo

Este artículo se inscribe en el proyecto de investigación con referencia HAR2015-65115-P (MINECO/FEDER).

1 manuel.tardio@urjc.es / ORCID iD: http://orcid.org/0000-0002$2712-2687$ de los electores. En las izquierdas se había logrado soldar una coalición nacional amplia que se conoció como Frente Popular y que iba desde el centroizquierda republicano hasta la izquierda obrera. Era una gran esperanza para los que habían sido derrotados en los comicios de 1933, puesto que ahora las candidaturas de unidad podían dar buenos resultados contando con que un sistema electoral mayoritario de grandes circunscripciones penalizaba severamente a quienes fueran en solitario. En las derechas no se había logrado todavía, ni se lograría, una coalición tan sólida, en parte por las diferencias entre monárquicos y cedistas, pero sobre todo porque los segundos también querían pactar con republicanos de centro y republicanos 
conservadores, táctica que no agradaba a los primeros. A mayor abundamiento, estaban las candidaturas que promovía el propio gobierno de Portela, los llamados candidatos centristas.

Aquel día 25 se celebraron muchos actos de propaganda por todo el país, como venía siendo habitual desde que se conociera la convocatoria de elecciones, dos semanas antes. Uno de ellos tuvo lugar en la capital catalana. Era uno de los primeros mítines de la candidatura de Esquerra que encabezaba Lluís Companys. Al parecer, uno de los oradores defendió ardorosamente posiciones separatistas y adornó su discurso con un lenguaje que el delegado gubernativo que asistía al evento consideró contrario a la Constitución. Así las cosas, mientras el orador atacaba el nacionalismo español, se escuchó también algún que otro grito de «iViva España!». Acto seguido, pistola en mano, el delegado intervino para suspender el mitin, justo cuando muchos de los asistentes habían empezado a cantar Els Segladors. ${ }^{2}$

Antes de que ese acto de campaña de la Esquerra desembocara en esa pequeña trifulca, entre las muchas palabras expuestas por los oradores se había podido escuchar una severa crítica al obispo de Barcelona, incluso alguna que otra palabra amenazante voz en grito, acusándole de estar interviniendo en la campaña. Lo que se recriminaba al obispo, entre otras cosas, era que hubiese recomendado tres días de rogativas en todas las iglesias de la diócesis para que Dios velara por los españoles en esas circunstancias, entendiendo que eso era tanto como ordenar a todos los párrocos de su jurisdicción que se mostraran lo más activos posible para conseguir que los feligreses comprendieran lo que estaba en juego y fueran a votar a las derechas. El obispo debía saber, según advirtió el orador, que ellos estaban tomando nota y que después de las elecciones llegaría el momento de ajustar cuentas, una vez consumado el triunfo de las izquierdas.

Esas críticas a la Iglesia o a alguno de sus prelados por hacer campaña durante las elecciones no fueron nada raras, especialmente entre los oradores socialistas y comunistas durante los actos del Frente Popular. Como venía siendo habitual desde que se proclamó la República, la cuestión religiosa se había instalado en la política española y formaba parte de los elementos de identidad ideológica a uno y otro lado del campo partidista. Para los candidatos de izquierdas, la Iglesia era uno más de los grupos de presión que actuaban en España para conseguir el triunfo de la CEDA e impedir la consolidación de la democracia republicana, tratando de abortar las reformas realizadas entre 1931 y 1933. Los "altos dignatarios de la Iglesia» eran protagonistas de las "actividades reaccionarias» que servían de soporte a la CEDA y sobre las que se levantaba la base del "fascismo» en España, a decir del líder comunista José Díaz. Aquella República «traída al empuje de la voluntad popular» en 1931 había estado más de dos años, según el orador socialista Julio Álvarez del Vayo, «bajo los resortes del odio y de la coacción» y al mando de "los elementos de un clericalismo brutal». ${ }^{3}$

Así pues, el papel de la Iglesia y, de forma más amplia, la división entre catolicismo y laicismo estuvo de nuevo

\footnotetext{
2 El Debate, 26-1-1936.

3 Mitin de José Díaz, en El Heraldo de Madrid, 2-1-1936. Mitin socialista en Badajoz, en El Socialista, 27-12-1935.
}

presente en la campaña electoral de 1936. Hasta ahora conocíamos algunos aspectos importantes de cómo la defensa del catolicismo o los postulados anticlericales formaron parte de los discursos de unos y otros. De hecho, contamos con investigaciones que han ponderado el peso del anticlericalismo en el lenguaje de las candidaturas del Frente Popular, así como otras que han resaltado la importancia del componente católico y la defensa de la fe y de la Iglesia como rasgos de la identidad de la propaganda derechista, fueran cedista, monárquica o carlista. Lo que, sin embargo, no ha sido sistematizado en su conjunto es el papel de la Iglesia, y más concretamente de algunos prelados y algunas juntas de Acción Católica, durante la campaña electoral, pues si bien el clásico libro de Javier Tusell sobre esas elecciones recoge algunos datos, lo hace de forma dispersa y subordinada a otros objetivos de estudio en el terreno de la sociología electoral y el análisis de las candidaturas. ${ }^{4}$

II

Al igual que el conjunto de las derechas, los católicos hicieron frente a las elecciones sin que se hubieran superado importantes divisiones internas. Pesaron las diferencias significativas entre los que habían apoyado el posibilismo de la CEDA, así como la política de coalición de este grupo con los republicanos radicales de Alejandro Lerroux durante los dos años anteriores, y los que estaban firmemente anclados al tradicionalismo monárquico del Bloque Nacional o el carlismo. La campaña confirmó que el balance que hacía cada uno de ellos de las políticas del segundo bienio no era coincidente. Sin embargo, las circunstancias pesaron mucho para resaltar lo que unía y no lo que dividía. De hecho, todos compartieron la misma opinión sobre el carácter decisivo de la consulta, tanto a corto plazo, acerca de la supervivencia de la influencia eclesiástica en el campo educativo y moral, como más a largo plazo, dentro de esa particular asociación entre catolicismo y la continuidad de la sociedad y la nación española que era intrínseca a buena parte del mundo conservador español de entonces. Así, el conjunto de la prensa católica lanzó un mensaje inequívoco sobre la situación a que se enfrentaban los católicos: «iHay que vencer a la revolución para defender los derechos de Dios y de la Iglesia!», podía leerse en un suplemento extraordinario publicado por El Debate en los primeros días de febrero. Ganar o perder en las elecciones significaba la victoria o la derrota ante el «marxismo y sus aliados», esos que buscaban, entre otros objetivos, "la ruina del nombre católico de España». ${ }^{5}$

Para ilustrar esta idea de encrucijada trascendental, se recurrió frecuentemente a los sucesos de Octubre de 1934,

4 Entre otros, algunos de los estudios fundamentales son: Álvarez Tardío 2002; Cruz 2006; López Villaverde 2008; Moral Roncal 2009; Salomón 2002; Tusell 1971. Véanse también los capítulos de J. de la Cueva, J. L. Ruiz Sánchez, F. Del Rey, M. Ostolaza y N. Townson en el volumen colectivo: Cueva Merino y Montero García 2009. En el ámbito regional, han aportado datos sobre la cuestión religiosa en la campaña electoral, investigaciones como las de Álvarez Rey 1993; Grandío Seonae 1998; Macarro 2000; Quirosa-Cheyrouze y Muñoz 1998; Rey Reguillo 2008; Sanz Hoya 2006; Valls 1992.

5 El Debate, 2-2-1936. 
tanto en los medios posibilistas como en las cabeceras monárquicas de $A B C$ o El Siglo Futuro. Al fin y al cabo, en ese momento lo de la «revolución» ya no era percibido por los católicos y su Iglesia como una simple cuestión retórica. Para ellos Octubre había sido la más clara demostración de las consecuencias prácticas de las ideas revolucionarias en el campo de la persecución de la religión. Y por si esto fuera poco, recurrieron asimismo a la comparación con la situación en países como Méjico o Rusia. Ellos, como explicaba la prensa cedista, no estaban dispuestos a rendirse ante quienes pensaban que lo del primer bienio había sido "solo un ensayo". Tal y como lo veían, una victoria del "frente revolucionario» significaba hacer que "España es como Méjico, como Rusia, oprobio de la civilización, sede de la barbarie y la tiranía». ${ }^{6}$

Los casos de Rusia y Méjico tuvieron una importancia evidente, en tanto que ambos facilitaron la ilustración de situaciones concretas en las que la idea de revolución había tenido consecuencias negativas para la vida de los creyentes y el normal desenvolvimiento de las actividades de culto y clero. $^{7}$ Los medios católicos trataron de convencer a sus lectores de que en España podría ocurrir lo mismo tras una victoria del Frente Popular, apelando una y otra vez a lo ocurrido en el Octubre asturiano de 1934. Como es sabido, las manifestaciones de anticlericalismo durante estos últimos sucesos habían sido notables, con algunas decenas de religiosos asesinados y en torno a medio centenar de iglesias destruidas o quemadas. Las imágenes de esta violencia y los relatos sobre las peripecias de los religiosos "martirizados» sirvieron para alimentar un discurso católico de campaña que fue la imagen contrapuesta de las descripciones frentepopulistas sobre la represión de Octubre. El de los católicos fue un relato que explotaba el miedo a los efectos que pudiera tener una amplia amnistía de los implicados en esa violencia y potenciaba una visión de las elecciones como una lucha por la supervivencia y no una simple alternancia democrática. Fotos de edificios religiosos saqueados e incendiados, narraciones sobre religiosas arrestadas y encarceladas, como las de la Casa del Pueblo de Turón, detalles sobre la muerte de los seminaristas de Oviedo o sobre las vejaciones sufridas por algunos religiosos en la vía pública, todo esto contribuyó a dotar de contenido un discurso caracterizado por el pánico a los revolucionarios anticlericales y por una visión simplista, pero eficaz en el terreno de la propaganda de masas, sobre la figura demoniaca y sacrílega del adversario izquierdista. ${ }^{8}$

\footnotetext{
6 Ídem.

7 Rusia, los bolcheviques y la persecución religiosa, en Pipes 1995: 337-368. Un resumen del caso mejicano, en Burleigh 2006: 160-163. Anticlericalismo en México, en De la Fuente 1997: 39-65. Un análisis comparado, en Cueva Merino 2012: 51-74.

8 Datos de la violencia anticlerical revolucionaria, en Montero Moreno 1998: 44-53. Reportajes e información de la prensa católica en ese mismo momento, en $A B C, 7,9,10,16$ y 21, 23-10-1934. Para la opinión católica fue especialmente importante lo ocurrido con el sindicato de Vicente Madera y el asalto a la Casa Social de Moreda en la noche del 4 al 5 de octubre de 1934. El relato de los hechos se publicó en toda la prensa y después en un libro de gran difusión: El Sindicato Católico de Moreda y la Revolución de Octubre (Madrid, 1935). Sobre Octubre, véanse los capítulos que contiene VV. AA. 1985. Sobre los socialistas y la insurrección: Avilés 2008: 129-157 y Souto 2013. Sobre la evolución socialista hasta las elecciones, véase Juliá 1977 y 1979.
}

Para entender la posición de la Iglesia durante la campaña electoral de 1936 y compararla con consultas anteriores, como las de junio de 1931 o noviembre de 1933, hay que tener presente que Octubre no solo despertó las iras de los católicos y su miedo a una vuelta al poder de las izquierdas, sino que también favoreció el discurso de los sectores integristas del catolicismo español; y todo esto frente a quienes, como el cardenal Vidal i Barraquer o el nuncio Tedeschini, habían defendido el posibilismo y trabajado a favor de un modus vivendi entre la Iglesia y el Estado republicano. Es decir, quienes venían criticando el accidentalismo y sostenían que la República era lo mismo que la revolución, se apoyaron en la violencia anticlerical de 1934 para intentar demostrar que ellos, y no los posibilistas, estaban en lo cierto. Además, los integristas denunciaron que el grueso de la legislación secularizadora del primer bienio había seguido vigente en 1935 y que los cedistas habían fracasado a la hora de modificar el artículo 26 de la Constitución. ${ }^{9}$

Por consiguiente, el fuego del discurso católico integrista se avivó a las puertas de la consulta electoral de 1936. Dentro de la Iglesia, esa resurrección se materializó, entre otros aspectos, en el ascenso del cardenal Gomá a la sede Primada, en perjuicio de la línea contemporizadora respaldada por el nuncio Tedeschini. El nuevo primado había publicado en los meses posteriores a Octubre una edición de sus pastorales y discursos precedida por un prólogo con el título significativo de Antilaicismo. En él describía lo que estaba pasando en España como parte de una lucha apocalíptica entre el bien y el mal, entre la revolución y la civilización. El catolicismo, decía, no era solo la esencia de la sociedad sino el guardián de la tradición y la historia de España, y sin la fe no había espacio para una cultura y una política nacionales. Por consiguiente, si la revolución era un ataque al «alma perdurable» del «pueblo» español, la obligación de los católicos era, según Gomá, «quitar la espina que se les había hincado en el alma y curar la herida que podría acarrearles la muerte». ${ }^{10}$

De este modo, el contexto en el que la Iglesia se preparó para participar en la campaña electoral de 1936 se caracterizó tanto por el miedo a la revolución como por un envalentonamiento del sector eclesiástico más opuesto a la línea posibilista de la nunciatura y más claramente enemigo del liderazgo posibilista de José María Gil-Robles. Es decir, una Iglesia fuertemente condicionada por el recuerdo y por la reconstrucción propagandística de los sucesos de Octubre

9 Los ataques contra la política de la CEDA, acusando a Gil Robles de hacer una rectificación tibia de la política del primer bienio, fueron constantes desde principios de 1934 en la prensa carlista: El Cruzado Español, El Pensamiento Navarro o El Siglo Futuro. Las críticas carlistas sobre la posible reforma constitucional auspiciada por la CEDA a mediados de 1935, en El Cruzado Español, 12-7 y 19-7-1935. En Moral Roncal 2009: 99 y 127. Política de la nunciatura y del cardenal Vidal, en Batllori, Duran y Solervicens 2003; García Prous 1996; Trullen Floria 2012; Vázquez García-Peñuela y Salido López 2007: 465-493.

10 Gomá y Tomás 1935: vol. I, «prólogo». Véase también: «Apología de la Hispanidad», discurso de Gomá en el Congreso Eucarístico Internacional en Buenos Aires, publicado por Maeztu en Acción Española, 11, 1934. Acción Católica se sumó también a la cruzada que sucedió a la revolución con el documento "Pro Ecclesia et Patria», en Razón y Fe, 104, 1934: 536-540. Un análisis político de las relaciones Iglesia-Estado en ese contexto, en Álvarez Tardío 2002: 309-310 y 314324. Sobre Gomá, véase la reciente biografía de Dionisio 2011. 
de 1934, así como por la influencia creciente de quienes no veían ningún futuro para el catolicismo dentro de la República. Además, se interpretó como un desastre que con motivo de las nuevas elecciones volvieran a ser legales las organizaciones socialistas, es decir, quienes, desde la perspectiva católica monárquica, habían «ensangrentado y arruinado la región asturiana» a base de "asesinatos, saqueos y otros crímenes». ${ }^{11}$

Ciertamente, nada de esto es comprensible si no se explica, también, que esos a quienes los católicos etiquetaban como revolucionarios no ocultaron sus objetivos. Durante la campaña electoral la cuestión anticlerical no fue primordial en los oradores de la izquierda republicana, más allá de defender la política educativa y secularizadora del primer bienio. Sin embargo, en los socialistas y los comunistas sí tuvo una impronta significativa. Interpretaron la revolución de Octubre como una acción defensiva contra el ascenso del fascismo; $y$, desde ese punto de vista, en las elecciones resultaba crucial frenar a los católicos en tanto que aliados o, simplemente, integrantes de ese fascismo entendido de forma genérica. Por eso, en el lenguaje socialista la Iglesia o los religiosos fueron presentados como copartícipes de "la reacción». La Iglesia, para ellos, era la otra cara de las clases represoras y de lo que veían como un fascismo vaticanista. Era, decían, una «iglesia beligerante» a la que atribuían intereses puramente políticos y un afán de poder que no se detenía ante nada, ni siquiera ante el uso de la violencia: «Si en sus manos estuviera, desde los campanarios dispararían los frailazos contra los que osan soñar con una vida civil plena, libre y alegre». ${ }^{12}$ Durante la campaña los socialistas alimentaron recurrentemente la imagen de una Iglesia aliada con la derecha y cuyo triunfo representaría la vuelta de la Inquisición, como explicaba una ilustrativa viñeta publicada a toda página el día 8 de febrero en El Socialista, en la que además podía verse a los curas hermanados con el «capital» y el "fascismo", y a un Vaticano "cruel, egoísta y tirano». ${ }^{13}$ Para ellos, la Iglesia era «un partido político más» que los banqueros, los usureros y los terratenientes, entre otros poderosos, utilizaban para comprar conciencias y ganar dinero. «En las próximas elecciones desatarán los clérigos una terrible ofensiva contra la democracia republicana». ${ }^{14}$ Los comunistas, por su parte, reclamaron abiertamente que aspiraban a "confiscar» las tierras de la Iglesia y de las Órdenes religiosas. Y que «el objetivo fundamental de la lucha revolucionaria por el Poder y la instauración del Gobierno Obrero y Campesino" llevaría a sus diputados a plantear en el futuro parlamento la «expulsión de las Órdenes religiosas y confiscación de sus bienes en beneficio de los parados», así como la implantación de la «instrucción laica» en condición de «obligatoria». ${ }^{15}$

III

Por lo que se refiere a los católicos y su Iglesia, las elecciones de 1936 fueron diferentes a las generales

11 Palabras de un titular de portada de $A B C, 23-10-1934$.

12 Editorial «Una iglesia beligerante», El Socialista, 4-2-1936.

13 El Socialista, 31-1-1936.

14 El Socialista, 4-2-1936.

15 Mundo Obrero, 10-2-1936. Documento electoral: «¿Por qué lucha el Partido Comunista?». celebradas en noviembre de 1933. En ambas se advierte el tono plebiscitario del discurso católico, en el sentido de apoyar o rechazar un republicanismo visto como esencialmente laicista y anticatólico. $\mathrm{Y}$ en las dos se mostraron las diferencias importantes entre el catolicismo posibilista, partidario de la contemporización y la revisión de la Constitución, y el catolicismo monárquico y tradicionalista, defensor sin más de la confusión de la Iglesia y el Estado y de otro régimen político. Sin embargo, en las de 1936 hubo un cambio. No es que los clérigos "desataran» esa «terrible ofensiva» contra la República de la que hablaba la prensa socialista, pero sí que algunos obispos tuvieron una presencia más clara y contundente durante la campaña. ${ }^{16}$

La Iglesia católica no hizo una campaña oficial para respaldar las candidaturas de un partido concreto. Pero sí hubo una importante movilización católica, apoyada por las palabras de varios obispos, para manifestar públicamente su apoyo a los candidatos que, según ellos, prometían la defensa de los derechos de la Iglesia. O mejor dicho, para hacer un llamamiento a los católicos para que no secundaran a aquellos candidatos que la opinión conservadora identificaba con el laicismo o una ideología revolucionaria. $Y$ fue especialmente activa en aquellos lugares donde resultaba más difícil la conciliación a favor de una candidatura derechista de unidad, de tal forma que el peligro de dispersión del voto católico era mayor.

Pocos días después de conocerse la convocatoria de nuevas elecciones, la Junta Diocesana de Acción Católica de Barcelona pidió públicamente la unión de todos los elementos de orden en defensa de los principios básicos de la sociedad. Lo que estaba en juego era la desunión de las fuerzas conservadoras en aquella provincia, en medio de una coyuntura que se consideraba decisiva: «en las próximas elecciones», afirmaban, "va a decidirse si en nuestra patria han de implantarse principios y procedimientos contrarios a la religión, a la familia, a la propiedad legítima y al orden social». Porque había "enemigos de la religión» que no dudaban en «decir que si triunfan será inmediata la implantación de aquellos principios» en una escala todavía mayor a la del primer bienio. Así pues, para los católicos barceloneses, puesto que el «enemigo» se presentaba "compacto", lo necesario era la agrupación de "todos los elementos de orden», dejando a un lado la «diversidad de matices políticos». ${ }^{17}$

De forma parecida se pronunció la Acción Católica de Granada. Estos empezaban asegurando que eran ajenos a la política de partidos, pero que la "gravedad del momento» les obligaba a pedir a los católicos que «depongan sus legítimas diferencias» y se "unan sin reversas en la próxima contienda electoral para defender a la Iglesia y a España». Desde su punto de vista, había que conjurar la posible dispersión

16 Sobre las elecciones de 1933, véase Villa García 2011: 269-279.

17 Ahora, 17-1-1936 y La Vanguardia, 16-1-1936. Los dirigentes de $A C$ de Barcelona señalaban que una "misión» obligada de su organización era «formar las conciencias de los católicos en orden a los problemas de alta política». Apelaban a las palabras de Pío XI, en la encíclica Dilectissima nobis, publicada en 1933, cuando había recomendado "vivamente a todos los católicos españoles» que se unieran «todos con grande disciplina en defensa de la fe». Por consiguiente, desde su punto de vista, ningún católico podía rechazar una «unión tan necesaria y urgente» para evitar que «triunfaran en las urnas las ideas revolucionarias». 
del voto conservador, y los católicos no podían dejar de «aportar con lealtad el voto y la colaboración a esta unión de partidos que pueda reconquistarnos la unidad nacional». Por consiguiente, todo menos ser «tristes cómplices de una revolución que viene contra todos y que los católicos, con la ayuda de Dios, todavía podemos conjurar». ${ }^{18}$

En el caso particular de Barcelona preocupaba bastante que la atomización de las derechas y la falta de acuerdo de esos grupos con la Lliga, favoreciera la victoria de la Esquerra. A eso respondía la nota comentada de Acción Católica, como también la temprana formación de una liga "Concordia pro Religión, Patria y Familia», que hizo suya esa nota y en cuyo manifiesto se explicaba que era una "agrupación apolítica» formada para "actuar en sentido unionista». ${ }^{19} \mathrm{Y}$ en esas circunstancias se explica, además, que esa misma semana de enero el obispo de Barcelona, Manuel Irurita, publicara una pastoral referida a la contienda electoral. El prelado calificaba la situación como de "gravísima necesidad" y señalaba expresamente que las "próximas elecciones» eran de "suma» importancia porque de ellas podía "depender hasta la misma existencia de la España católica». No era ésta una apreciación excepcional en el mundo católico, que durante toda la campaña repitió, aunque con matices variados, este mensaje apocalíptico, en el que la victoria del Frente Popular se identificaba con la desaparición del catolicismo. Frente a eso, decía el obispo, se trataba de hacer lo posible para que triunfaran «Jesús y su Iglesia»..$^{20}$

La pastoral no era solamente una llamada de atención a los católicos para influir en su voto. Apareció muy pronto y eso se debió, sobre todo, a que una de sus principales finalidades era apelar a los grupos políticos catalanes para que se hiciera "la unión de todos, posponiendo cada uno sus demás ideales, por legítimos que sean», es decir, algo muy parecido a lo que había señalado la Acción Católica de la ciudad condal. En ese sentido, no es extraño que pocos días más tarde la prensa republicana atribuyera al obispo de Barcelona el mérito de haber convencido al catalanista conservador Francisco Cambó de que la unión con el resto de las derechas era necesaria, en un momento en el que las negociaciones corrían peligro por el deseo de la Lliga de no presentar candidaturas conjuntas en una misma circunscripción. ${ }^{21}$

La relación entre la actividad de la Acción Católica y la confección de las candidaturas del bloque contrarrevolucionario fue un hecho evidente en el caso de Barcelona. Fernando Valls y Taberner, vicepresidente de la Junta diocesana, dimitió de ese cargo a finales de enero por «haber sido incluido en la candidatura para diputados por la circunscripción de Barcelona». En otras provincias también hubo una relación significativa entre la actividad de la Acción Católica y la elaboración de candidaturas contrarrevolucionarias. El comité provincial de Acción Católica de Santander se reunió a mediados de enero para acordar la presentación de tres candidatos en las próximas elecciones. Y en la nota subsiguiente explicaba que ya se habían «llevado a efecto las primeras negociaciones para

\footnotetext{
18 El Debate, 22-1-1936.

19 El Debate, 18-1-1936.

20 El Heraldo de Madrid, 17-1-1936.

21 Política, 22-1-1936.
}

una inteligencia de derechas» con la Agrupación Regional Independiente, que proponía «una coalición de fuerzas católicas y auténticamente derechistas de la Montaña ».22

Por consiguiente, en algunos casos como Granada, Barcelona oSantander lasasociaciones católicas participaron, directa o indirectamente, en la campaña electoral. Y esa participación, en aquel contexto y desde el punto de vista de las izquierdas, constituyó una demostración clara de que la Iglesia no era neutral. Así, desde el lado de la izquierda azañista, se dijo que la Acción Católica y la CEDA eran dos aliados preparados para "romper el fuego» contra el Frente Popular y que, los primeros se habían quitado «la careta con que tantas veces disimuló las intenciones del organismo vaticanista" ${ }^{23}$

Con todo, no parece que lo habitual durante la campaña fuera un comportamiento tan explícito como el que tuvieron las juntas diocesanas de las provincias de Granada o Barcelona. De hecho, si bien la Acción Católica había sido importante en la movilización de los simpatizantes conservadores que habían apoyado a la CEDA en los años anteriores, también es cierto que esa organización había insistido a menudo en su carácter apolítico, habiendo mostrado, incluso, su rechazo a la movilización política de los jóvenes. Que se tomaran más o menos en serio ese apoliticismo dependió, sin duda, de la posición del prelado de cada diócesis. Así, en Valladolid, donde el obispo Gandásegui era cercano a los posibilistas, no parece que la línea seguida durante las elecciones fuera similar a la de Irurita. En ese sentido, es sintomático que el párroco de Medina del Campo se quejara, en enero de 1936, de que las mujeres de Acción Católica no tenían autorización del prelado para implicarse en la movilización política de esos días. ${ }^{24}$

En la segunda quincena de enero la actividad de la Acción Católica por todo el país fue muy significativa. En esos días se celebraron muchas reuniones y conferencias de las Juntas locales de AC. Las de Navarra, por ejemplo, se caracterizaron por la afluencia de "numeroso público». Pero los contenidos de las reuniones no fueron de carácter político, al menos formalmente. En uno de los actos más concurridos el presidente de la Junta de AC de Pamplona insistía, significativamente, en señalar «el error de quienes suponen que Acción Católica es un partido político». ${ }^{25}$ La mayor parte de los discursos y actividades se centraban en cuestiones pastorales y en una recurrente presencia de la interpretación católica de la historia de España, siempre, siguiendo los tópicos al uso en el tradicionalismo católico español, es decir, identificando la gloria imperial pasada con el ideal religioso, a la vez que responsabilizando al enciclopedismo y la masonería de la decadencia nacional. No había, por tanto, referencias concretas a las elecciones, aunque sí puede interpretarse como parte de un discurso

\footnotetext{
22 La Vanguardia, 25 y 15-1-1936, respectivamente.

23 Política, 18-1-1936.

24 Sobre el apoliticismo formal de las Juventudes de AC y lo difícil que resultó mantenerlo, especialmente el Octubre revolucionario, véase Watanabe 2003: 224-230 y 263. La compleja relación entre el apoliticismo formal de la Acción Católica y su papel en la formación de las nuevas elites juveniles del conservadurismo católico, está bien reflejado en el análisis del caso de Valladolid, en Berzal de la Rosa 2008: 222-228. Párroco de Medina del Campo, en ibídem: 229.

25 El Debate, 18-1-1936.
} 
político la insistencia en que los católicos debían hacer todo lo posible por «hacer resurgir a España, forjar la conciencia colectiva, instaurar el imperio de la espiritualidad, restablecer las tradiciones que hicieron que el mundo nos admirase». ${ }^{26}$

Por consiguiente, la relación entre la Acción Católica y la actividad electoral de los grupos conservadores fue equívoca y cambiante en función de las circunstancias de cada diócesis y la actitud de los prelados. Una relación más estrecha y explícita habría planteado algunos problemas a la Iglesia, a sabiendas de que el voto católico estaba dividido entre los que seguían apoyando al posibilismo y quienes denunciaban la esterilidad de esa postura. Quizás por eso no hubo una declaración colectiva del episcopado, al estilo de las que se publicaron en el año 1931, pero a finales de enero de 1936, justo cuando restaban dos semanas para la consulta, el cardenal primado, Isidro Gomá, publicó un documento en el que señalaba el camino a los católicos españoles.

Durante su último viaje a Roma, Gomá había recibido un encargo del papa ante la inminente consulta electoral en España: trabajar por la unidad de los católicos. Nada más regresar, a mediados de enero, redactó el documento Nuestra vuelta de Roma, que se publicó en la prensa los últimos días de ese mismo mes. Tuvo consecuencias muy notables tanto entre los católicos como en las izquierdas, aunque cada uno de ellos hiciera una interpretación diferente. En los segundos provocó una reacción airada, especialmente entre los socialistas. Gomá cumplió el encargo del papa y pidió una "unión de los católicos» ante las elecciones porque estaban en juego "los derechos de la Iglesia», "el saneamiento de la escuela» y "la santidad de la familia». La unión debía durar tanto cuanto durase la "la hostilidad del adversario» y debía traducirse «en todas las formas legítimas» que aquel adoptase «en su ataque o en la defensa de principios o hechos contrarios» a las creencias de los católicos. ${ }^{27}$

Como resultado de este planteamiento, el primado no dudó en pedir a los católicos que estuvieran unidos en el voto a los partidos que defendiesen los intereses del catolicismo. Lo hizo, además, apelando a la lógica del sistema democrático, pues si el «instrumento forjador de la irreligión» era "el voto de los laicos», la mejor forma de «contrarrestar la acometida» debía ser «la suma de los votos y de los partidos de afirmación religiosa, yendo a la conquista del Poder político para la tutela de los intereses del orden religioso». Gomá tenía una visión de las elecciones como un proceso que serviría, a corto plazo, para abrir o cerrar la puerta a un laicismo que él consideraba veneno puro para la existencia de la Iglesia. Y su idea de "orden religioso» permanecía anclada en postulados tradicionalistas para los que era necesario disponer de un poder político que protegiera al catolicismo. Al fin y al cabo, se había «realizado un esfuerzo colosal para separarnos de Dios», dijo Gomá, y era necesario que España le fuera «devuelta» a Jesucristo. ${ }^{28}$

26 Conferencia de José María Taboada, vocal de la Junta Central de AC de Pamplona. El Debate, 19-1-1936. Un análisis de las actitudes tradicionalistas de los católicos españoles, en Redondo 1993: 245-355. En el ámbito de pensamiento político, sobre católicos, grupos monárquicos y tradicionalismo, véase González Cuevas 1998.

27 Los entrecomillados de la pastoral, en este párrafo y los siguientes, proceden de $A B C$, Ahora y La Vanguardia, números del 30-1-1936. El encargo del papa al primado, en Dionisio 2014: 29.

28 Palabras de la pastoral citada anteriormente.
Además, y de forma un tanto paradójica, el primado añadió unas palabras advirtiendo sobre los momentos de gran «agitación política» que se vivían en el país y como, por parte de los católicos, debía "evitarse toda violencia» y había que «respetar la libertad de quienes no piensen como vosotros». La Iglesia no tenía nada "que oponer a la diversidad de partidos políticos», pero solo reconocía el derecho de los católicos a votar dentro de la pluralidad de quienes no tuvieran un programa "contrario a las doctrinas de la Iglesia». Con esto, obviamente, el primado evitaba optar entre monárquicos y cedistas. Es más, por lo que la pastoral no decía, que también es importante, se puede deducir que el nuevo director de la Iglesia española no tenía mucho interés en mediar entre una familia católica fuertemente dividida. Sus palabras no amparaban explícitamente la doctrina del posibilismo, lo que es significativo. Tampoco se pronunciaba inequívocamente contra la República, aunque criticaba que "casi un lustro de régimen nuevo" la "nave del Estado» no se había estabilizado y que "la paz de los espíritus» seguía estando ausente. ${ }^{29}$

Probablemente, el cardenal Vidal i Barraquer, primera voz de los prelados en España durante los años previos, no habría firmado un documento como ese. Y no lo habría hecho no solo por lo que decían algunos párrafos sino, sobre todo, por lo que Gomá se había callado, evitando mostrar alguna generosidad con el esfuerzo realizado por los sectores templados de la derecha católica entre 1933 y 1935. Es llamativo que la petición de unidad de Gomá diera por hecho que todos los fieles comulgaban con un balance de la política del segundo bienio en el que estaba ausente cualquier valoración positiva de la política radical-cedista. No obstante, también es importante recalcar que esa pastoral fijaba unos objetivos muy limitados para la unión de los católicos, consciente el primado de cómo estaba el patio dentro de la Iglesia y las fuerzas conservadoras. Esto fue algo especialmente comentado por los editorialistas de El Debate. El principal documento público de la Iglesia de cara a las elecciones pedía respeto a los derechos de la Iglesia y protección de la escuela católica y de la familia, pero nada más. No incluía una sola palabra sobre otros aspectos que podían dividir a la opinión derechista, como el alcance de una reforma constitucional o la cuestión de un posible modus vivendi entre la Iglesia y el Estado. Por eso los accidentalistas, haciendo una lectura interesada y obviando lo que no les gustaba de la pastoral de Gomá, dijeron que "nadie que se afirme racionalmente católico» podía discrepar de los objetivos fijados en esa carta. Y es que, pese a todo, era una pastoral "de mínimos» centrada en un mensaje contundente a favor de la unidad de los candidatos conservadores. Destilaba tradicionalismo, pero Gomá no pudo ir más allá, puesto que no había recibido el visto bueno de Roma para respaldar una unión de los católicos basada en la propuesta de los monárquicos acerca de un programa conjunto de gobierno y de iniciativa constituyente..$^{30}$

29 Ídem.

30 Compárense las editoriales de $A B C, 30-1-1936$ y El Debate, 31-11936. Sobre la dispersión de la oferta derechista y sus diferencias ideológicas y tácticas, véanse: Gil Pecharromán 1984: 101-135. Robinson 1973: 404-412. 
IV

El pronunciamiento de Gomá incentivó la publicación de documentos similares por parte de los prelados, en sus respectivas diócesis. Aunque no pasó en todas partes, hubo una decena de obispos que dictaron pastorales de orientación en el contexto de la campaña. Fueron suficientes como para amplificar la percepción de que la Iglesia había decidido entrar en campaña con más fuerza que en años anteriores; los «obispos electoreros» - por usar una expresión habitual en la prensa de la izquierda republicana durante aquellos días - irrumpían en las elecciones para insistir en el mensaje del primado: la unidad de los católicos ante la «delicada situación política». ${ }^{31}$

Uno de los primeros fue el obispo de Oviedo, Justo Antonio de Echeguren, que habló abiertamente de los deberes de los católicos «por razones de religión, en el orden político». Recordó que ser buenos creyentes y buenos ciudadanos era una y la misma cosa, por lo que en el comportamiento político también había que «promover el bien» de la Iglesia y ajustar "su actuación a las normas de la religión y de la moral». Los medios adecuados eran los que fueran «lícitos», pero el objetivo principal consistía en "la instauración de un orden social cristiano conforme a las enseñanzas de la Iglesia». ${ }^{32}$

Este tipo de documentos estaban en la línea de lo que la Iglesia española y el papado venían recordando a los católicos desde el año 1931, esto es, que un comportamiento coherente era el de aunar la defensa del orden social cristiano y la acción política. Ahora, sin embargo, se ponía el acento en algo que Gomá había remarcado: la situación política era grave y los creyentes no podían permitirse el lujo de estar divididos. Como dijo el obispo de Córdoba, Adolfo Pérez Muñoz, estaba en juego la existencia misma de la patria española y los «pastores de almas» tenían el «deber» de "levantar la voz para advertir el grave peligro actual y los medios de conjurarlos». O en palabras más apocalípticas, las del obispo de Teruel, Anselmo Polanco, en las elecciones se enfrentaban las «dos ciudades enemigas de que habla San Agustín»: "Luchan, de un lado, los defensores de la religión, de la propiedad de la familia; del otro, los representantes y voceros de la impiedad, del marxismo y del amor libre». En una línea similar se manifestaron los obispos de Tortosa, Málaga o Santander, que además insistieron a los sacerdotes que pronunciaran "oraciones» y tuvieran otros gestos dentro de la liturgia para lograr que todos los «militantes» de la Iglesia coadyuvaran "al triunfo de la verdad» en aquellos «momentos en que la Iglesia y nuestra Patria se hallan privados de sacratísimos derechos». ${ }^{33}$

Esta insistencia pastoral ponía de relieve, también, que algunos prelados estaban inquietos ante lo que percibían como desapego de sus fieles hacia los dictados de la Iglesia y el riesgo de que la fractura entre monárquicos y posibilistas condujera a la presentación de candidaturas por separado, perjudicando así la fortaleza de la defensa de la religión

31 "Obispos electoreros», en El Heraldo de Madrid, 13-2-1936.

32 El Debate, 31-1-1936l y La Vanguardia, 1-2-1936.

33 Córdoba, en $A B C$ y El Heraldo de Madrid, ambos del 1-2-1936. Tortosa, en $A B C, 7-2-1936$. Málaga y Santander, en El Debate, 7-2-1936. Circular del obispo, en El Noticiero, 14-2-36, cit. en Tusell 1971: 278. frente a las izquierdas. No en vano, que obispos como el de Almería se aprestaran a amonestar a los católicos para que defendieran «en las próximas elecciones los intereses sacratísimos de la religión y de la patria» indica, así, que no siempre estaba claro que esa defensa fuera a producirse motu propio y en los términos en los que la Iglesia creía necesario. ${ }^{34}$

Por otra parte, otros prelados, encabezados por el de Tarragona, no siguieron el camino marcado por Gomá, lo que sugiere que, seguramente, el sector posibilista de la Iglesia, el que a las órdenes del nuncio Tedeschini había apoyado la contemporización en las relaciones entre la Santa Sede y el gobierno español, hubiera preferido que la Iglesia permaneciera en un segundo plano durante la campaña. Es decir, que no se dieran motivos a las simpatizantes del Frente Popular, en un contexto tan complejo y de alta politización, para reforzar sus posiciones anticlericales. ${ }^{35}$

El hecho de que varios obispos se mostraran preocupados por la desunión política de sus fieles e incitaran públicamente a la movilización católica, tuvo como consecuencia lógica una mayor presencia pública de asociaciones confesionales o de grupos diocesanos. La más contundente fue, de nuevo, la Junta Diocesana de Acción Católica de Barcelona que, en consonancia con lo explicado más arriba, hizo público un documento una semana antes de las elecciones. En él hablaba de los peligros para la religión, la familia y el orden social que representaba un triunfo de «la revolución" y pedía a todos los católicos que fueran conscientes de su "deber de conciencia de votar» y que respaldasen la candidatura de orden. ${ }^{36}$ También fueron especialmente activas, en esa misma línea, las asociaciones de padres ligadas al ámbito de la educación católica. Así, la Asociación para la Defensa y Libertad de los Padres en la Educación de los Hijos advirtió de que el programa del Frente Popular recogía el cierre de colegios católicos y la expulsión del crucifijo de las escuelas, por lo que pidió expresamente el voto a quienes defendían «los supremos intereses de la religión, la familia y la libertad de los padres en la educación de sus hijos». La Federación Católica de Maestros no se quedó atrás y publicó un manifiesto en el que aseguraba haberse visto obligada a «intervenir en la lucha actual ante el proceder de otras organizaciones profesionales» que se habían "puesto de parte del bloque revolucionario». Se refería a importantes asociaciones de docentes ligadas a los grupos del Frente Popular, especialmente a los socialistas, que, según sus datos, estaban pidiendo dinero a los maestros para fines puramente electorales. Ante eso y recordando también pasados episodios de violencia anticlerical como los de mayo de 1931 u octubre de 1934, apelaban al voto "por España» y respaldaban abiertamente las candidaturas antirrevolucionarias. ${ }^{37}$

Del mismo modo, algunos curas tuvieron una implicación directa en actividades como la de la Acción Católica

34 Almería, en El Heraldo de Madrid, 13-2-1936. Fragmentación de candidaturas derechistas, en Álvarez Tardío 2015: 53-68; Gil-Robles 2006: 403-436; Tusell 1971: 135-154.

35 Esa línea se puede apreciar en algunos detalles de las relaciones de la nunciatura con el nuevo gobierno de la izquierda republicana tras las elecciones. Véase Álvarez Tardío y Villa García 2013: 683-764.

36 Barcelona, en Ahora y La Vanguardia, ambos de 9-2-1936.

37 Padres, en $A B C$ y El Debate, ambos de 31-1-1936. Docentes, en El Debate, 6-2-1936 y La Vanguardia, 7-2-1936. 
barcelonesa, es decir, se involucraron en la campaña electoral de un modo más directo que a través de la oración. Les animaron los pronunciamientos de sus obispos y el hecho constatable de que la prensa que leían habitualmente repetía una y otra vez la idea de unas elecciones apocalípticas para el futuro de los católicos. En aquella sociedad de los años treinta, en la que la Iglesia venía de ser protegida oficialmente por el Estado, la participación de los sacerdotes en la política partidista era vista, por todas las izquierdas pero también por ámbitos del centro y centro-derecha como un acto inadmisible, incluso como una manifestación de antirrepublicanismo. Ciertamente, no era un lenguaje muy propio de una Iglesia ajena a la lucha de partidos, el hecho de afirmar, como se hacía en una hoja parroquial, que: "Dios está siempre con los cristianos, y las izquierdas son enemigas de Cristo». ${ }^{38}$

Por eso la prensa de izquierdas no solo criticó las declaraciones públicas de los obispos, sobre todo la pastoral del primado, sino que convirtió en denuncias de impureza electoral las quejas que le llegaban de los candidatos frentepopulistas sobre la actividad política de los párrocos. Algunas de esas denuncias estaban débilmente fundamentadas o se referían a actuaciones que no eran ilegales, como es el caso de unas «beatas» de Tablado (Oviedo), a las que se criticaba por hacer proselitismo entre las mujeres y enfrentarse a su párroco, que consideraban demasiado liberal. ${ }^{39}$ Otras eran más precisas en cuanto a la acción propagandística de los religiosos, como la que se refería al cura de Dacón (Orense), por dedicarse en la misa del domingo a «dar el consejo de que nadie votase más que candidaturas de derechas si no querían verse expuestos a que el Gobierno se incautase de sus propiedades». O la que explicaba que en la hoja parroquial de Castropol (Oviedo) se pedía el voto para el «partido de Cristo». Y también había referencias a párrocos que hacían propaganda electoral desde el púlpito, como los de Quinto (Zaragoza), Peñalva (Huesca) o Piloña (Oviedo). En algún caso, como el párroco de Piñor (Orense), se denunciaban no solo sus predicaciones sino también la organización de «manifestaciones derechistas» y la propaganda directa a favor de candidatos cedistas apelando a los beneficios que los mismos podían traer para la localidad en cuestión. Y del cura de Lezuza (Albacete) se decía que había convertido "la casa de Dios en un chamizo pegajoso y maloliente», es decir, que preparaba engrudo en la Iglesia para utilizarlo en carteles con fines electorales. ${ }^{40}$

Fueran más o menos concretas o estuvieran mejor o peor probadas, todas estas denuncias dieron mucho juego en la campaña de las organizaciones del Frente Popular. Porque sirvieron para mostrar a la opinión pública de izquierdas la imagen de una Iglesia católica aferrada a sus privilegios y que «utiliza las cátedras sagradas para hacer propaganda política». Al fin y al cabo, los medios socialistas reprochaban a los obispos lo que consideraban como una conducta hipócrita: ni política social, ni preocupación por el pobre, ni fe verdadera ni nada, sino solo una «Iglesia

\footnotetext{
38 Según denuncia publicada en El Heraldo de Madrid, 30-1-1936.

39 El Heraldo de Madrid, 7-2-1936.

40 Dacón y Castropol, en El Heraldo de Madrid, 30-1-1936. Quinto, en El Socialista, 6-2-1936. El resto, en El Heraldo de Madrid, 12-2-1936 y 14-2-1936.
}

beligerante» dispuesta a todo para reconquistar el país y el Estado. ${ }^{41}$

Las denuncias de curas implicados en la campaña afectaban a un porcentaje muy pequeño del conjunto de sacerdotes del país, que eran varios miles. Sin embargo, hay indicios de una relación precisa entre algunos párrocos y la movilización conservadora de aquel febrero de 1936. Uno es que numerosos actos públicos organizados por la CEDA o por sus juventudes contaron con el apoyo público, casi siempre indirecto, de los curas locales, que no dudaron en participar en las misas que los precedían y en bendecir determinadas campañas. Así ocurrió en un mitin que encabezó Dimas de Madariaga en Sonseca, Toledo, que estuvo precedido de una misa oficiada por el sacerdote Mariano Ruiz Roldán, y donde acto seguido «el cura párroco del pueblo, señor Rivera, bendijo los locales» de Acción Popular e incluso "pronunció un breve discurso, al que contestó el señor Madariaga». Y esto no fue una excepción, pues la bendición por parte de los párrocos de nuevos locales de las JAP (Juventudes de Acción Popular) o de las secciones femeninas de AP era algo habitual, llegando a participar también algún obispo. El de Coria, por ejemplo, presidió un acto religioso en Cáceres cargado de fuertes tintes políticos, destinado básicamente a bendición de la enseña provincial de las juventudes populares. También el Consejo Nacional de las JAP, celebrado en Alcalá de Henares a mediados de diciembre de 1935 , fue precedido de una misa en la iglesia Magistral de esa localidad. ${ }^{42}$

Por otra parte, hubo algunos pocos casos de párrocos que desobedecieron a sus superiores y decidieron hacer política de forma clara y precisa, es decir, presentándose a las elecciones. Fueron excepcionales pero es innegable que tuvieron cierta repercusión pública en ámbitos regionales. Como el canónigo lectoral de la catedral de Málaga, Ismael Rodríguez Orduña, que trató de presentarse a las elecciones con "carácter independiente» y publicó un manifiesto contra el "bloque de derechas» y con algunos ataques a las izquierdas. O el caso más conocido del canónigo Jerónimo García Gallego, candidato anticedista, que según la prensa socialista fue suspendido "ad divinis» por el obispo de Segovia «por rebeldía contra leyes y disposiciones eclesiásticas». ${ }^{43}$

Tanto por lo que expresaron algunos obispos en sus pastorales, como por la situación de confrontación política que se vivía y los antecedentes de la política del primer bienio, no es extraño que algunos párrocos y religiosos vieran el Frente Popular como un conglomerado de izquierdas caracterizado, antes que nada, por un laicismo

41 Cátedras sagradas, en El Heraldo de Madrid, 30-1-1936. Editoriales representativas del tema anticlerical como potente argamasa de las izquierdas, en El Socialista y El Heraldo de Madrid, 31-11936. Propaganda electoral socialista, en El Socialista, 4, 7 y 8-2-1936. Sobre 20 viñetas del cartel del 8 de febrero, ocho estaban dedicadas a denunciar el clericalismo en alguna de sus facetas. Se señalaba a menudo que la represión de Octubre había estado dirigida por el fascismo vaticanista.

42 Toledo, en J.A.P., no 44, 7-12-1935. Cáceres, en J.A.P., no 46, 28-12-1935. Alcalá, en J.A.P., no 45, 21-12-1935. Otros, en J.A.P., no 44, 7-12-1935.

43 Málaga, en El Sol, 12-2-1936. García Gallego, en El Socialista, 12-2-1936. Véase también Moreno Cantano 2014: 47-70. 
anticatólico. ${ }^{44}$ Por eso y por lo que se señala a continuación, algunos curas debieron de interpretar esas pastorales como autorizaciones, sino instrucciones directas, para hacer política desde el púlpito. De hecho, hubo unos pocos casos que confirman la implicación de algunos curas en la lucha electoral, aunque también la negativa de la jerarquía a respaldarlos, llegando incluso a afearlos por ciertas conductas. Así, el cura de Villar del Pedroso (Cáceres) se mostró dispuesto a hacer campaña a favor de que los fieles votaran íntegra la candidatura antirrevolucionaria, como le escribió a su superior, pero este se mostró contrario. El párroco de San Agustín de Guadalix (Madrid) hizo "todas las gestiones posibles» para lograr el mayor número posible de votos a las derechas. Algunos párrocos de Granada mostraron en privado su orgullo por la forma en que sus fieles acudían a misas especiales para pedir al Señor «el triunfo de la fe», llegando a estar convencidos de que ganarían las derechas en toda la provincia. ${ }^{45} \mathrm{Y}$ en algunas parroquias gallegas sus titulares se convirtieron en agentes electorales, como pasó con el párroco de Villagarcía de Arosa, en Pontevedra, que a decir de una sentencia judicial posterior se vio envuelto en una disputa con el delegado municipal el mismo día de las votaciones. ${ }^{46}$

Para comprender el ambiente de politización que se adueñó de algunas parroquias, resulta significativo el hecho de que algunos obispos, e incluso la nunciatura, recibieran peticiones concretas de políticos conservadores para que autorizaran a las monjas de clausura a salir el 16 de febrero para ir a votar. Así ocurrió con el presidente de las Juventudes de Acción Popular de Oropesa, preocupado porque «en esta localidad el elemento obrero tiene alguna fuerza" y debía aportarse "todos los recursos para el triunfo antirrevolucionario». Lo mismo hizo el presidente de Acción Agraria Manchega en Alcázar de San Juan, convencido de que diez o doce votos eran fundamentales en una situación en la que «triunfo o derrota son de vida o muerte para todos cuantos vivimos defendiendo la Religión y al orden social». ${ }^{47}$ En una línea similar, la abadesa de un convento de La Puebla de Montalbán (Toledo) contaba al cardenal que en el pueblo les pedían «que salieran a votar». Y el cura de Villarrobledo (Albacete) explicaba a su superior que algunas señoras de Acción Popular le habían rogado que solicitara el permiso para que las religiosas pudieran votar. Porque, como escribía el 8 de febrero el arcipreste de Huéscar (Granada), «en la lucha terrible entablada con la revolución todos los votos son pocos». ${ }^{48}$

Pese a todo esto, las instrucciones enviadas desde los obispados fueron, en general, explícitas en sentido contrario a lo que se pedía. Así, una circular remitida a

44 Como los curas de Villar del Pedroso o de Huéscar, dentro de la diócesis de Toledo. Archivo de la Diócesis de Toledo (ADT), Secretaría, 1936, varias fechas. Véase Dionisio 2014: 52. También González Gullón 2011: 412-414.

45 Madrid, carta de 31-1-1936, en Expediente personal de Gonzalo Osorio Pedrosa, ACCAM, XV, A o 2.2. Cit. en González Gullón 2011: 314. Otros, en ADT, Secretaría, 1936, varias fechas. Cit. en Dionisio 2014: 52. En Huéscar se celebró un solemne triduo pidiendo «el triunfo de la fe».

46 Archivo Histórico Nacional, Tribunal Supremo, Leg. 171, exp. 884.

47 Cartas al nuncio Tedeschini del 6-2-1936. Archivo Secreto Vaticano (ASV), Nunz. Madrid, b 967, Fasc. 4.

48 Todo, en ADT, Secretaría, 1936, varias fechas. Cit. en Dionisio 2014: 52 las religiosas, tanto de clausura como de congregaciones, prohibía explícitamente el permiso para ir a votar. $Y$ es que para algunos prelados había una línea que delimitaba la diferencia entre, de un lado, llamar a los católicos a mantenerse unidos antes las elecciones, presentando candidaturas antirrevolucionarias que defendieran los derechos de la Iglesia y, de otro, animar a los religiosos a implicarse directamente en la campaña. Fue una línea tenue, que a veces se traspasó, como corroboran algunos datos ya comentados. Sin embargo, las órdenes cursadas desde la nunciatura fueron claramente contrarias a todo lo que supusiera ignorar esa línea. Así, significativamente, el ocho de febrero, el nuncio Tedeschini pidió al obispo de Zamora que aplicara el derecho canónico a rajatabla y no concediera autorización a ningún reverendo para presentarse por alguna de las candidaturas en liza, tampoco las conservadoras. ${ }^{49}$

Por último, algunos prelados llamaron a la unidad de los católicos ante las elecciones, pero las acciones concretas que reclamaban se referían a actos litúrgicos y no a acciones políticas de campaña, si bien la interpretación que se hizo desde ámbitos del Frente Popular no fue esa. La principal cabecera del PSOE denunció al obispo de Sevilla, cardenal Ilundain, por haber irrumpido en la campaña advirtiendo que: "toda conciencia honrada debe votar a las derechas y que si así no es, el caos se adueñará de España». ${ }^{50}$ La circular efectivamente publicada por el Boletín Oficial del Arzobispado de Sevilla recogía, en términos parecidos a los de otros prelados, que la "situación por que atraviesa la religión y la iglesia católica en España» era "grave y dolorosa». Pero Ilundain pedía que, ante el hecho de haberse "convocado un nuevo Parlamento legislativo, cuyas deliberaciones» habrían de ser decisivas en un futuro, los «diocesanos» recordaran «su obligación cristiana de acudir a la oración fervorosa y humilde demandando de Dios, en cuyas manos estamos todos, los auxilios oportunos en la presente necesidad». Es decir, que el prelado no llamaba explícitamente a sus párrocos a hacer campaña desde el púlpito, sino que exhortaba «a todos los fieles y de modo especial a sacerdotes y religiosas a que redoblen sus oraciones a fin de que Dios nos conceda lo que sea más conveniente a la religión y a la sociedad y que no permita se agraven los males que ya padece la religión y la iglesia católica». ${ }^{51}$ Esa línea que no ocultaba el interés de la Iglesia en una victoria de los antirrevolucionarios, pero que no mezclaba deber católico del voto con acción política del clero, se pudo ver también en otras pastorales, como la del obispo de Tarazona, que solicitaba un "fervor excepcional» en las "oraciones ordinarias de cada día, añadiendo otras extraordinarias» por "el triunfo de iglesia en las cercanas elecciones». ${ }^{52}$

49 Circular a las religiosas, en ídem. Nunciatura, en ASV, Nunz. Madrid, b. 912b, doc. 773. Poco le importó al nuncio que no solo el prelado, sino también el mismo presidente de las Cortes, Santiago Alba, le pidieran una excepción para el caso de Ismael Rodríguez.

50 El Socialista, 6-2-1936.

51 Ahora, 26-1-1936, El Debate, 26-1-1936, La Vanguardia, 25-1-1936.

52 Pastoral del obispo de Tarazona y administrador apostólico de Tudela, publicada en El Pensamiento Navarro, 7-2-1936. Tusell 1971: 287-288. 


\section{V}

Durante la campaña de 1936, los católicos españoles pudieron comprobar que la Iglesia veía la situación política con extraordinaria preocupación, no solo por lo que entendían que se jugaban en esa convocatoria de elecciones sino también por la inquietud con que asistían a la división entre monárquicos y cedistas. Hacer frente a ambos desafíos y aunar esfuerzos fue el objetivo que hizo movilizarse al cardenal primado, en parte obedeciendo órdenes directas del papa y en parte desautorizando a la nunciatura, partidaria de una mayor discreción. Además, un número significativo de prelados se implicaron directamente en la campaña electoral porque entendieron que estaba en juego mucho más que la aplicación de la legislación secularizadora del primer bienio. Y lo hicieron de forma más activa en aquellas diócesis, como Barcelona, donde su titular era menos dado a la política contemporizadora de los accidentalistas, a la vez que se mostraba preocupado por la división de las candidaturas conservadoras.

Sin embargo, oficialmente la Iglesia se movió con cierta prudencia para no contribuir más a la fragmentación del voto católico y no presentarse como una institución abiertamente beligerante contra el régimen. No en vano, la división entre las derechas españolas se había acentuado durante el segundo bienio, especialmente por las fuertes críticas de los monárquicos a la actuación de la CEDA y por las diferentes opiniones que suscitó el empeño del sector accidentalista de la jerarquía en promover las negociaciones entre el gobierno y la Santa Sede. Así las cosas, el Vaticano, aparte de promocionar a Gomá y tomar la importante decisión de dar por muertas las negociaciones para un modus vivendi hasta ver la composición del nuevo parlamento, tampoco hizo nada para apoyar a unos u otros de forma explícita. Y ningún portavoz oficial del Vaticano desautorizó expresamente la línea accidentalista y la política cedista del segundo bienio, ni siquiera después de lo ocurrido en octubre de 1934. De hecho, durante 1935 se habían sucedido algunas muestras de que los posibilistas contaban todavía con importantes apoyos dentro de la Iglesia. Avvenire d'Italia, un medio próximo al Vaticano, había apoyado la alianza entre republicanos radicales y católicos cedistas, a la vez que calificaba de ilusorios y peligrosos los procedimientos del líder de Renovación Española, Antonio Goicoechea. ${ }^{53}$ Por consiguiente, por mucho que disgustara a los monárquicos y los carlistas, Roma no se mostró dispuesta a dar ningún paso que supusiera identificar a la institución con una sola de las familias de la derecha española. Ciertamente, la Iglesia católica seguía siendo, pese al tono apocalíptico en que se presentó la propaganda electoral derechista, una organización donde no había unanimidad de opiniones en el campo de las relaciones con el régimen republicano. La batalla en pro de la unidad antirrevolucionaria durante la campaña no era equivalente a suscribir en bloque las críticas de los carlistas y los monárquicos contra los cedistas.

53 Archivo del Ministerio de Asuntos Exteriores, R-288, 9-7-1935. El artículo fue comentado así por el entonces embajador español en la Santa Sede, Pita Romero: «a mi juicio significa la autorizadísima repulsión de las campañas de Época, $A B C$ y Siglo Futuro, así como las de los monárquicos en general. Puede considerarse que ésta es la opinión de Vaticano dada la significación de las personas que intervienen en la alta dirección de este periódico».
Así, es elocuente que en aquellas circunstancias Fal Conde, Secretario de la Comunión Tradicionalista, se dirigiera por carta al Secretario de Estado del Vaticano, cardenal Pacelli, para transmitirle su tremendo enfado porque consideraba que la mayoría de los obispos eran ajenos a la opinión de su organización. O que el cardenal Segura admitiera, poco después de las elecciones, que el apoyo de Pacelli a la política sostenida por Tedeschini era difícilmente quebrantable. ${ }^{54}$ Todo esto revela que la posición del integrismo dentro de la Iglesia era menos sólida de lo que las izquierdas pudieron percibir en esas semanas y de lo que pudo dar a entender la ajetreada actividad de algunos prelados y de sus párrocos para llamar a los católicos a la participación electoral por el triunfo de la fe y la unidad antirrevolucionaria.

\section{BiBLIOGRAFÍA}

Álvarez Rey, L. 1993. La derecha en la Il República: Sevilla, 1931-1936. Sevilla: Universidad.

Álvarez Tardío, M. 2002. Anticlericalismo y libertad de conciencia. Política y religión en la Segunda República española (1931-1936). Madrid: Centro de Estudios Políticos y Constitucionales.

Álvarez Tardío, M. 2015. «Un momento decisivo. La estrategia de la CEDA ante las elecciones de 1936». Bulletin d'Histoire Contemporaine de l'Espagne 51: 53-68.

Álvarez Tardío, M. y Villa García, M. 2013. «El impacto de la violencia anticlerical en la primavera de 1936 y la respuesta de las autoridades». Hispania Sacra LXV 132: 683-764.

Avilés, J. 2008. «Los socialistas y la insurrección de Octubre de 1934». Espacio, tiempo y forma 20: 129-157.

Batllori, M., Duran, E. y Solervicens, J. 2003. L'Església i la II República Espanyola: el Cardenal Vidal i Barraquer. Valencia: Eliseu Climent.

Berzal de la Rosa, E. 2008. "Acción Católica en Valladolid durante la Segunda República», en F. Montero García (coord.), La Acción Católica en la II República: 205-230. Alcalá de Henares: Servicio de Publicaciones de la Universidad de Alcalá.

Burleigh, M. 2006. Causas sagradas. Política y religión en Europa. De la Primera Guerra Mundial al terrorismo islamista. Madrid: Taurus.

Cruz, R. 2006. En el nombre del pueblo. República, rebelión y guerra en la España de 1936. Madrid: Siglo XXI.

Cueva Merino, J. de la. 2012. «El asalto de los cielos: una perspectiva comparada de la violencia anticlerical española de 1936». Ayer 88: 51-74.

Cueva Merino, J. y Montero García, F. (coords.). 2009. Laicismo y catolicismo. El conflicto político-religioso en la Segunda República. Servicio de Publicaciones de la Universidad de Alcalá.

De la Fuente, G. 1997. "Clericalismo y anticlericalismo en México, 1810-1938». Ayer 27: 39-65.

Dionisio, M. A. 2011. Isidro Gomá ante la dictadura y la República. Toledo: Instituto Teológico San Ildefonso.

Dionisio, M. A. 2014. El clero de Toledo en la primavera de 1936. Toledo: Instituto Teológico San Ildefonso.

García Prous, C. 1996. Relaciones Iglesia-Estado en la segunda República española. Sevilla: Obra Social y Cultural Caja Sur.

Gil Pecharromán, J. 1984. «El alfonsismo radical en las elecciones de febrero de 1936». Revista de Estudios Políticos 42: 101-135.

Gil-Robles, J. M. 2006. No fue posible la paz. Barcelona: Ariel.

Gomá y Tomás, I. 1935. Antilaicismo. Barcelona.

González Cuevas, P. C. 1998. Acción Española. Teología política y nacionalismo autoritario en España (1913-1936). Madrid: Tecnos.

González Gullón, J. L. 2011. El clero en la Segunda República. Madrid, 1931-1936. Burgos: Ed. Monte Carmelo.

54 Archivo Fal Conde, en Archivo General de la Universidad de Navarra, caj. 272, exp. 10. En el extenso comentario en Moral Roncal 2009: 216. Lo de Segura, en ibídem: 221. 
Grandío Seonae, E. 1998. Los orígenes de la derecha gallega: la CEDA en Galicia (1931-1936). La Coruña: Edicios Do Castro.

Juliá, S. 1977. La izquierda del PSOE (1935-1936). Madrid: Siglo XXI.

Juliá, S. 1979. Orígenes del Frente Popular en España. Madrid: Siglo XXI.

López Villaverde, L. 2008. El gorro frigio y la mitra frente a frente. Construcción y diversidad territorial del conflicto político-religioso en la España republicana. Valencia: Rubeo.

Macarro, J. M. 2000. Socialismo, República y Revolución en Andalucía (1931-1936). Sevilla: Universidad.

Montero Moreno, A. 1998. Historia de la persecución religiosa en España: 1936-1939. Madrid: BAC.

Moral Roncal, A. M. 2009. La cuestión religiosa en la Segunda República española. Iglesia y carlismo. Madrid: Biblioteca Nueva.

Moreno Cantano, A. C. 2014. «Jerónimo García Gallego (1893-1961): canónigo, diputado y propagandista», en F. Montero García, A. C. Moreno Cantano y M. Tezanos Gandarillas (coords.), Otra Iglesia. Clero disidente durante la Segunda República y la guerra civil: 47-70. Gijón: Ed. Trea.

Pipes, R. 1995. Russia under the Bolshevik Regime. Nueva York: Vintage Books.

Quirosa-Cheyrouze y Muñoz, R. 1998. Católicos, monárquicos y fascis tas en Almería durante la Segunda República. Almería: Instituto de Estudios Almerienses.

Redondo, G. 1993. Historia de la Iglesia en España. 1931-1939. Tomo I. La Segunda República 1931-1936. Madrid: Rialp.

Rey Reguillo, F. del. 2008. Paisanos en lucha. Exclusión política y violencia en la Segunda República española. Madrid: Biblioteca Nueva.
Robinson, R. A. H. 1973. Los orígenes de la España de Franco. Derecha, República Revolución, 1931-1936. Barcelona: Grijalbo.

Salomón, P. 2002. Anticlericalismo en Aragón. Protesta popular y movilización política (1900-1939). Zaragoza: PUZ.

Sanz Hoya, J. 2006. De la Restauración a la reacción. Las derechas frente a la Segunda República (Cantabria, 1931-1936). Santander: Universidad de Cantabria.

Souto, S. 2013. "Octubre de 1934: historia, mito y memoria». Hispania Nova 11. [Texto electrónico].

Trullen Floria, R. 2012. Religión y política en la España de los años treinta. El nuncio Federico Tedeschini y la Segunda República. Zaragoza: Institución Fernando el Católico.

Tusell, J. 1971. Las elecciones del Frente Popular. Madrid: Edicusa. [2 volúmenes].

Valls, R. 1992. La derecha regional valenciana (1930-1936). Valencia: Edicions Alfons el Magnánim.

Vázquez García-Peñuela, J. M. y Salido López, M. M. 2007. «Algunos datos nuevos sobre las relaciones Iglesia-Estado durante la Segunda República Española: documentación inédita del Nuncio Tedeschini en el ASV». Ius Canonicum 47: 465-493.

Villa García, R. 2011. La República en las urnas. Madrid: Marcial Pons.

VV. AA. 1985. Octubre: cincuenta años para la reflexión. Madrid: Siglo XXI.

Watanabe, Ch. 2003. Confesionalidad católica y militancia política: La Asociación Católica Nacional de Propagandistas y la Juventud Católica Española (1923-1936). Madrid: UNED. 